Resumo

Este artigo objetiva discutir o uso do desenbo como ferramenta auxiliar na constituição subjetiva de uma paciente autista, cujo caso foi estudado por meio da seleção e interpretação de desenhos significativos para a sua compreensão. Por meio do conbecimento teórico vinculado à interpretação dos desenhos, constatou-se que tal produção gráfica foi relevante no que se refere à constituição subjetiva da paciente em questão. É possivel dizer que, após o inicio das atividades lúdicas, a paciente obteve condições de desfrutar de algum controle sobre o Outro, diferenciando-se dele.

Descritores: autismo; constituição; desenho; psicanálise.

\section{A INFLUÊNCIA DO \\ DESENHO NA CLÍNICA PSICANALÍTICA PARA A CONSTITUIÇÃO DO SUJEITO: UM ESTUDO DE CASO SOBRE O AUTISMO INFANTIL}

\section{Renata Cristina Gonçalves}

DOI: http//dx.doi.org/10.11606/issn. 1981-1624.v22i2p230-245.

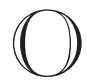

termo "autismo" foi cunhado em meados de 1911 pelo psiquiatra Paul Eugen Bleuler, que empregou a expressão para se referir à perda de contato com a realidade como característica da esquizofrenia. Em 1943, Leo Kanner apresenta a ideia sobre um "autismo infantil precoce", no qual afirmava que tais indivíduos apresentavam algumas especificidades próprias.

Em seu artigo intitulado "Os distúrbios autísticos do contato afetivo", Kanner (1943/1997) se interessou por onze crianças consideradas portadoras de retardo mental, visto que não se encaixavam em nenhum diagnóstico. Kanner, ao analisar essas

Psicóloga. Mestre em Linguística Aplicada e Estudos da Linguagem pela Pontifícia Universidade Católica de São Paulo (PUC-SP), São Paulo, SP, Brasil. 
crianças, percebeu que mantinham comportamentos semelhantes.

O distúrbio fundamental mais surpreendente "patagônico", é "a incapacidade destas crianças de estabelecer relações" de maneira normal com as pessoas e situações desde o princípio de suas vidas. Seus pais falavam delas nestes termos: desde sempre, criança "se bastando a si mesma"; "como em uma concha"; "mais contente sozinha"; "agindo como se os outros não estivessem lá"; "totalmente inconsciente de tudo que a rodeia"; "dando a impressão de uma sabedoria silenciosa", "fracassando em desenvolver uma sociabilidade normal"; "agindo quase como sob hipnose". Não se trata, como nas crianças ou adultos esquizofrênicos, de uma ruptura de relações previamente estabelecidas; não se trata de um "retraimento" sucedendo uma participação (Kanner, 1943/1997, p. 156).

Atualmente, a classificação nosológica do transtorno autista depende exclusivamente dos sintomas existentes em determinado indivíduo, segundo os manuais de psiquiatria. A partir dessas descrições nosológicas é possível constatar que os manuais psiquiátricos consideram as manifestações comportamentais e sintomatológicas de um indivíduo, exclusivas para o fechamento de um diagnóstico, que consequentemente designam-no a uma classificação.

De acordo com Ansermet (2003), a psicanálise se ocupa da ideia de sujeito, ou seja, ainda que a criança possua um distúrbio orgânico ou uma síndrome genética, isso não a exclui da condição de sujeito, pois apesar das consequências orgânicas/genéticas, este representa um ser que sofre: "Não podemos vê-lo apenas como alguém que manifesta um defeito orgânico ou mental, segundo a lógica da deficiência" (p. 82). Dessa maneira, há de se expor os riscos atrelados às concepções comportamentais.

A psicanálise configura o autismo para além de sua sintomatologia, ou seja, seu interesse volta-se a outros aspectos: "Dentro da perspectiva psicanalítica lacaniana, na criança autista, haveria uma falha no estabelecimento da relação especular com o Outro primordial, o que resultaria num fracasso da constituição do sujeito" (Rêgo \& Carvalho, 2006, p. 13). 
Rêgo e Carvalho (2006) afirmam que a criança autista frequentemente não é elevada ao estatuto de sujeito devido à dificuldade em ingressar na linguagem, sendo essa a condição para a constituição subjetiva.

Conforme Jerusalinsky (2012), para que ocorra a constituição subjetiva é imprescindível que o bebê faça presença nas fantasias da mãe, antes mesmo de ser gerado, para que "toda essa engrenagem que a antecede se ponha efetivamente em movimento" (p. 83). Os olhares, gestos e palavras do Outro proporcionarão condições para o esboço do mapa libidinal do corpo da criança. Nesse momento, o sujeito é convocado a advir, uma vez que há suposição de sujeito, não o sujeito do inconsciente, dividido, mas antecedente a este. Vorcaro e Lucero (2010) assinalam que há sujeito a partir do momento em que se direciona a fala a essas crianças, por meio dos significantes do Outro, à medida que esse ser é representado, ainda que não tenha sido inscrito no simbólico.

Lacan (1979) afirma que há o surgimento de "um novo sujeito" após o fechamento do terceiro tempo do circuito pulsional.

É preciso bem distinguir a volta em circuito de uma pulsão do que aparece - mas também por não aparecer, - num terceiro tempo. Isto é, o aparecimento de ein neues Subjekt que é preciso entender assim - não que ali já houvesse um, a saber, o sujeito da pulsão, mas que é novo ver aparecer um sujeito. Esse sujeito, que é propriamente o outro, aparece no que a pulsão pôde fechar seu curso circular (p. 169).

Segundo Bruder e Brauer (2007), o Outro, por meio de sua fala, possibilita que a criança tenha acesso aos significantes e submeta-se a estes, de modo que será capturada pelo significante. Eis aí o processo de alienação.

A alienação é a operação na qual o sujeito é convocado a produzir-se no campo do Outro, a preço de uma perda de ser. O sujeito se faz representar por um significante, sob pena de desaparecer sob ele.... Pela separação, o sujeito livra-se do efeito afanísico da concatenação significante e, segundo Lacan, experimenta outros efeitos que não os de sentido com que um discurso solicita. Na separação, o sujeito se depara com o desejo do Outro, efetivamente. Ao contrário da alienação, na qual se trata de um "destino", de "escolha forçada", a separação diz respeito a um "querer", isto é, de um ato que supõe um tirar-se desta condição de realizar-se no Outro (Novaes, 2004, p. 91).

É possível encontrar na teoria freudiana o que em Lacan é definido como processo de alienação e separação. Vejamos: Freud (1914/1996), em seu artigo "Os instintos e suas vicissitudes", propôs movimentos de constituição subjetiva ao designar três tempos no circuito pulsional:

232 Estilos clin., São Paulo, v. 22, n. 2, maio/ago. 2017, 230-245. 
(a) O olhar como atividade dirigida para um objeto estranho. (b) O desistir do objeto e dirigir o instinto escopofílico para uma parte do próprio corpo do sujeito; com isso, há ... o estabelecimento de uma nova finalidade - a de ser olhado. (c) Introdução de um novo sujeito diante do qual a pessoa se exibe a fim de ser olhada por ele (p. 135).

O primeiro tempo do circuito pulsional é aquele em que o bebê é ativo, volta-se para um objeto externo (a mãe/o seio da mãe). No segundo tempo, a pulsão é direcionada a-si-próprio (para determinada parte do corpo, que se torna o substituto do objeto da fase anterior). O terceiro tempo é o de "fazer-se para o outro", fazer-se objeto de desejo do outro: o bebê clama pelo olhar do agente materno.

Após o fechamento do terceiro tempo do circuito pulsional, pode-se dizer que ocorre a alienação, uma vez que a criança se oferece como objeto de desejo do Outro. É imprescindível que a pequena criança se torne objeto de gozo do Outro para vir a ser desejante (momento que corresponde ao de separação). A experiência da ausência da mãe inscreve a falta no circuito pulsional: "Na separação ... a falta marca o Outro e o sujeito.... O desejo do adulto é tomado pela criança como um enigma. Trata-se da saída do lugar de objeto do Outro para o de sujeito" (Lopes \& Bernardino, 2011, p. 379).

Entretanto, nesse processo pode haver complicações. Se é no "enxame significante produzido no campo do Outro" que está o lugar prévio em que o sujeito pode aparecer como efeito da linguagem, pode acontecer que ele fique reduzido a esse lugar, funcionando como signo - como "significante paralisado" (Vorcaro \& Lucero, 2010). Em termos lacanianos, o autista se reduz ao $S^{1}$, a esse significante que não faz cadeia, ou, ainda, $S^{1}$ não é ressignificado. Quando $\mathrm{S}^{2}$ emerge, o par se solidifica em holófrase: mesmo que haja fala, não há intervalo entre os significantes, não há espaço para a emergência do sujeito.

Veja que o autismo decorre de uma dificuldade na relação especular entre Outro e bebê, ou seja, o que fracassa é a alienação ao Outro. Para Catão (2009), o bebê deve abdicar a posição de ser o objeto de gozo da mãe, de ser tudo para ela (deve admitir a falta), para que emerja como 
significante. Entretanto, o que acontece no autismo é que há recusa de ser, antes de mais nada, o objeto de desejo da mãe. Compreende-se, desse modo, a ecolalia como expressão maior do autismo: a repetição estereotipada da fala do outro não diz de alienação, mas sim de uma tentativa de "proteção" por parte da criança, uma vez que o Outro se apresenta como invasivo.

Para Jerusalinsky (2012), tais estereotipias são barreiras à constituição subjetiva. Em relação à linguagem há exclusão: modo que o autista encontra de situar-se em relação à linguagem.

Dessa maneira, pode-se dizer que o autista interrompeu seu processo de constituição subjetiva, paralisando-se no segundo tempo do circuito pulsional. Há fracasso no circuito, este não se completa.

Ao referir-se ao segundo tempo do circuito pulsional, é relevante ressaltar que esse tempo é sancionado pelo direcionamento da pulsão ao próprio corpo, e se é justamente nesse momento que a criança autista "paralisa", talvez esse fato evidencie a relação intrigante dessas crianças com seus corpos.

Isso permitiria explicar as paradoxais condutas corporais dos autistas, que parecem não sofrer fisicamente, como se não tivessem corpo. Ora, eles não têm corpo, já que ter corpo pressupõe que se aceite essa inscrição do ser na metáfora proposta pelo Outro. $O$ autista não tem corpo porque não está enlaçado ao Outro, mesmo que ele seja totalmente refém do significante (Nominé, 2001, p. 19).
Segundo Ribeiro e Monteiro (2004), as automutilações e estereotipias no autismo referem-se às maneiras de manejar o gozo, visto que este se apresenta em excesso: "é o fato de as crianças autistas se baterem, não terem noção do perigo e agirem como se não tivessem um corpo. O corpo da criança autista parece não lhe pertencer, permanecendo um corpo estrangeiro" (Abramovitch, 2001, p. 83).

Apesar do gozo no corpo, Corgosinho (2001) aponta que as brincadeiras ritualizadas do autista não demonstram interesse ao corpo ou à própria imagem, pois quando despertam algum interesse são pelos objetos que ali se refletem no espelho, no qual evidenciam a falta de identificação com o outro, pois a criança se mistura a esses objetos como se fossem uma só unidade.

No autismo, há algo que não se constitui no momento em que o sujeito é chamado a falar. Pode-se pensar em fracasso da especularização e em não-organização da imagem do corpo próprio, construção necessária e operada pelo reconhecimento do outro primordial, que, pelo olhar, cria e antecipa a imagem totalizante que deverá ser capturada com júbilo pelo bebê (Nascimento, 2001, p. 58).

Quanto às repetições e a fala do autista - fala que não é direcionada -, parecem funcionar em uma tentativa de negar ao Outro e não o demandar. A ecolalia não recebe status de patologia na psicanálise, 
uma vez que toda manifestação de fala está submetida ao funcionamento da linguagem.

Ainda que não haja fala no autista ou qualquer outra criança, Dolto (2008) ensina que o desenho é um tipo de produção gráfica que possibilita a comunicação com o terapeuta. Desenhar é um modo de expressão, pois ao exercer tal atividade as crianças representam simbolicamente suas fantasias e como se posicionam diante do mundo.

A autora se refere à atividade do desenho como substituta da associação livre (técnica de investigação psicanalítica) do adulto, como auxílio para que a criança expresse por meio de produções gráficas aqueles momentos, tanto os que lhe foram importantes como os aflitivos. Além disso, é imprescindível que haja conversação com a criança no tocante ao seu desenho, de modo que tal produção se apresente envolta de significações mesmo quando a criança não diz nada a seu respeito.

Estas produções da criança são, assim, verdadeiros fantasmas representados, de onde são decodificáveis as estruturas do inconsciente. Eles são só decodificáveis, enquanto tais, pelos dizeres da criança que antropomorfiza, que dá vida às diferentes partes de seus desenhos, a partir do momento em que fala a este respeito à analista. É o que há de particular na análise de crianças: aquilo que nos adultos é decifrado a partir de suas associações de ideias sobre um sonho contado, por exemplo, pode ser ilustrado, nas crianças, por aquilo que dizem sobre os grafismos e as composições plásticas, suportes de seus fantasmas e de suas fabulações em sua relação de transferência (Dolto, 2008, p. 2).

Ainda que a criança não possua uma imagem integral do próprio corpo, esta é capaz de transmitir algo sobre suas representações acerca dos próprios grafismos, uma vez que faz parte da aposta do analista compreender que "qualquer desenho, qualquer representação do mundo, já é uma expressão" (Dolto, 2008, p. 19).

É nesse sentido que o estudo de caso de Maria ${ }^{1}$ se configurou, a partir do objetivo de discutir sobre o uso do desenho no processo de constituição subjetiva da paciente em questão. Assim, foram coletados e selecionados desenhos durante as sessões de terapia que permitissem o levantamento de reflexões a seu respeito.

A interpretação dos desenhos realizou-se a partir da seleção daquelas produções que evidenciavam possíveis indícios de constituição subjetiva de Maria. Para que houvesse maior fidedignidade na interpretação de tais produções gráficas, assegurou-se que neste estudo caberia a descrição de algumas sessões, da ação da terapeuta e da paciente, visto que ao se limitar apenas às interpretações das produções gráficas corre-se o risco de perder ações e interações que fazem parte de tal processo. As interpretações dos desenhos foram realizadas pela própria terapeuta com os professores e psicanalistas da instituição envolvida. 


\section{Caso clínico}

Maria deu início ao tratamento psicológico na Clínica de Psicologia do Centro Universitário de Lavras (Unilavras) em abril de 2012. As sessões ocorreram uma vez por semana no período de aproximadamente um ano e seis meses.

As primeiras sessões procederam com Lourdes ${ }^{2}$ - mãe de Maria - e evidenciavam as dificuldades que ocorreram quanto ao diagnóstico de autismo, concedido pelo neurologista da filha. Em entrevista, Lourdes relata a história de vida da paciente. Vejamos:

Maria nasceu na zona rural no interior de Minas Gerais. Insatisfeita com as condições de moradia, Lourdes mudou-se para a cidade quando sua filha apresentava poucos meses de idade. Devido à frágil relação entre Lourdes e o marido, Maria mantinha pouco contato com o pai, e este, por sua vez, constituiu uma nova família. Lourdes fala sobre seu estranhamento com Maria quando ela completou dois anos de idade: não respondia quando chamada, não brincava com outras crianças ou adultos e não demonstrava nenhum tipo de afeto ou emoção.

Aos três anos e meio Maria ingressou em uma escola, onde uma funcionária recomendou a Lourdes que levasse a filha ao psiquiatra, devido aos comportamentos "idiossincráticos" de Maria. A partir de então, Maria foi acompanhada por um psiquiatra. Os exames neurológicos não constataram anormalidade, mas aos cinco anos de idade Maria recebeu o diagnóstico de autismo pelo neurologista. Em seguida, ela foi encaminhada para a Associação de Pais e Amigos dos Excepcionais (Apae) da cidade.

Aos seis anos Maria foi matriculada em uma escola regular, mas permaneceu em atendimento na Apae. Suas atividades escolares estacionaram no primeiro ano do ensino fundamental, no qual Maria permaneceu por cinco anos, ou seja, até completar onze anos de idade. Após esse período, Maria afastou-se da escola regular e permaneceu apenas em atendimento na Apae (até os doze anos). Lourdes relata que nessa época Maria demonstrava períodos de agressividade

236 Estilos clin., São Paulo, v. 22, n. 2, maio/ago. 2017, 230-245. 
e hiperatividade, que acarretaram seu afastamento da instituição. Lourdes relacionava tais períodos à ausência do pai, pois pai e filha mantinham contato até Maria completar dez anos. Lourdes afirmava que tal afastamento contribuiu para o agravamento do quadro clínico de Maria.

Durante o acompanhamento psicológico de Maria, houve sessões separadas com Lourdes, que também iniciou a terapia. Contudo, o trabalho desenvolvido com a mãe da paciente não será discutido, uma vez que o ponto central do artigo é dialogar a respeito da constituição subjetiva de Maria.

Após quatro meses de atendimento, recebo a notícia de que Lourdes veio a falecer. Até a suspensão do tratamento, Maria se apresentava sob responsabilidade da tia materna, à espera da guarda judicial.

\section{Constituição subjetiva de Maria com base em suas produções gráficas}

A primeira vez que estive com Maria notei que ela evitava a todo momento olhar para mim, não respondia quando chamada pelo nome e parecia não notar minha presença. A primeira sessão se resume basicamente ao “jogo" que Maria realiza por meio dos lápis, canetas e gizes que manuseava ao chão. Ela os manipulava, mas sem nenhum interesse de exploração - os objetos apenas passavam por suas mãos, sem provocar-lhe nenhum interesse. As sessões com Maria eram envoltas em silêncio e movimentos de balanço.

Durante as sessões atentei-me à dificuldade de Lourdes em reconhecer Maria como sujeito, pois Lourdes sempre dizia da incapacidade da filha diante de alguma brincadeira. Seicman (2000), ao se referir à "aposta antecipatória", menciona as fantasias do Outro, isto é, crer em uma subjetividade que ainda não existe, mas que está por vir. A partir dessa ideia, parece que essa aposta fracassa na relação mãe-filha.

Ao início do segundo mês de terapia, consigo aproximar-me de Maria, visto que me junto a ela no chão, manipulo os objetos da mesma maneira e repito seu balanço no mesmo ritmo. A partir desse momento, Maria nota minha presença - interrompe sua atividade quando nota meus movimentos semelhantes. Em seguida, cesso meus movimentos igualmente, e é nesse descompasso que obtenho o primeiro olhar e sorriso de Maria.

Ainda nessa sessão, coloco algumas folhas em branco ao chão. Lourdes diz que Maria não sabe escrever nem desenhar. Pergunto a Maria se ela gostaria de desenhar, e logo ela senta-se à mesa. Ela inicia com movimentos circulares, colorindo, e em meio às garatujas surge seu primeiro desenho com forma. Seus movimentos dão forma a um rosto (Figura 1, ao lado direito da folha). Ao questioná-la sobre sua produção, ela diz ser um gatinho. 


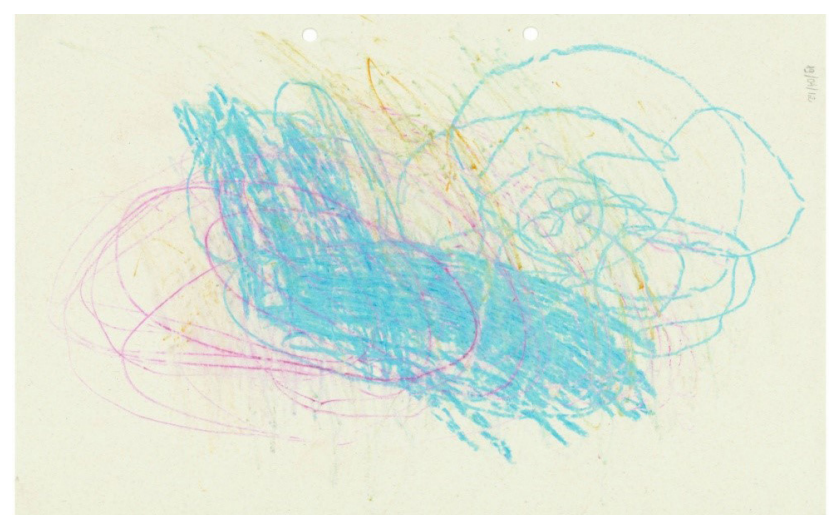

Figura 1. Gatinho.

Fonte: Prontuário de atendimento da Clínica-Escola de Psicologia do Unilavras.

Na próxima sessão, Maria impede minha presença em suas brincadeiras e atira alguns objetos contra a parede. Após algum tempo, Maria direciona-se até mim, chama-me repetidas vezes de mãe e permanece a olhar fixamente para mim. Essa cena gera incômodo em Lourdes que logo ameaça sair da sala. Nessa sessão, o misto de agressividade e afetividade revelam a transferência, e, ao partir para a produção gráfica, Maria esboça algumas pétalas dizendo-me serem flores (Figura 2).

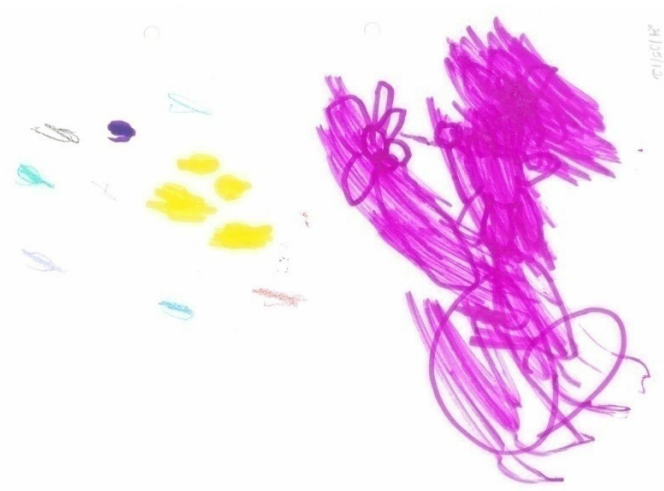

Figura 2. Flores.

Fonte: Prontuário de atendimento da Clínica-Escola de Psicologia do Unilavras.

238 Estilos clin., São Paulo, v. 22, n. 2, maio/ago. 2017, 230-245. 
Os desenhos de Maria recebem formas e contornos, havendo o mínimo de organização simbólica, havendo um esboço de imagem corporal que é recoberto quando Maria o risca. Parece que o simbólico ainda é algo avassalador para ela.

Diversas vezes, durante as brincadeiras estereotipadas, Maria mostra-se agressiva; porém, noto que quando Maria manifesta algum tipo de agressividade, logo novos significantes surgem em suas produções, como se essa expressão lhe proporcionasse algum tipo de elaboração. A partir dessa observação, deparei-me, em meio às flores desenhadas por Maria, com um corpo. Ainda que ela não afirmasse ser um corpo, é possível identificá-lo ao lado esquerdo do desenho (Figura 3).

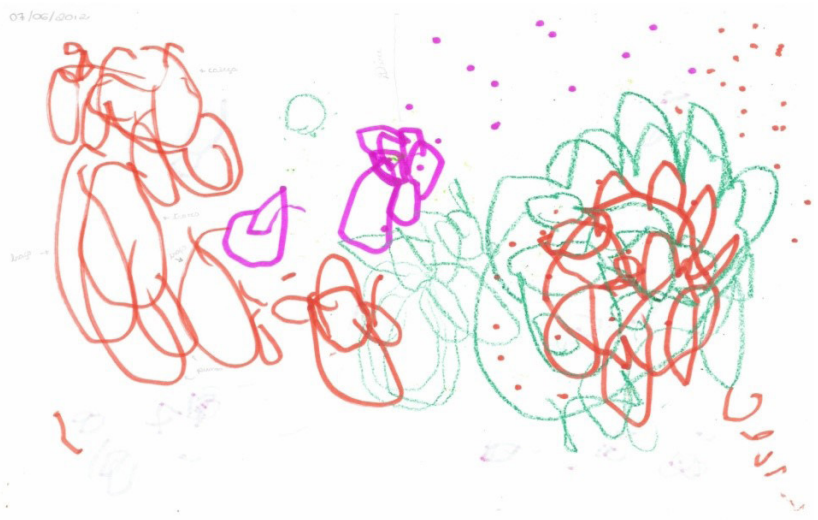

Figura 3. Corpo.

Fonte: Prontuário de atendimento da Clínica-Escola de Psicologia do Unilavras.

É graças à nossa imagem do corpo sustentada por - e que se cruza com - nosso esquema corporal que podemos entrar em comunicação com outrem. Todo o contato com o outro, quer o contato seja de comunicação ou para evitá-la, é submetido pela imagem do corpo; pois é na imagem do corpo, suporte do narcisismo, que o tempo se cruza com o espaço, e que o passado inconsciente ressoa na relação presente (Dolto, 2008, p. 15).

A partir da análise do desenho, é possível pensar em uma estrutura de esquema corporal. Ainda que o desenho proporcione o esboço de um corpo precário (com poucos detalhes), dá boa ideia de corpo, o próprio corpo, ao se considerar a ideia de Dolto (2008) sobre a imagem corporal antes da passagem pelo Complexo de Édipo, visto que o autista ainda não perpassou por esse período. 
A imagem do corpo - antes do Édipo - pode projetar-se em toda representação, qualquer que seja, e não apenas nas representações humanas. É deste modo que um desenho ou uma modelagem de coisa, vegetal, animal, ou humano é, simultaneamente, imagem daquele que desenha, tais como ele os desejaria, em conformidade com aquilo que ele se permite esperar deles (Dolto, 2008, p. 21).

Ao início do quarto mês com Maria, recebo a notícia que sua mãe Lourdes veio a falecer e que Maria estava sob os cuidados da tia materna.

Em meados do quinto mês, as flores (Figura 4) reaparecem, visto que havia algum tempo não as desenhava. Assim que desenha sua última flor, Maria faz movimentos circulares, perpassa a borda da folha e continua os movimentos sobre mesa. Seus movimentos ao desenhar as flores parecem uma forma de descarga, haja vista que para a execução dos outros desenhos (flores) Maria utilizou força exacerbada e, para os círculos, leveza e suavidade. É possível observar como as flores demonstram maior uso de força que os movimentos circulares.

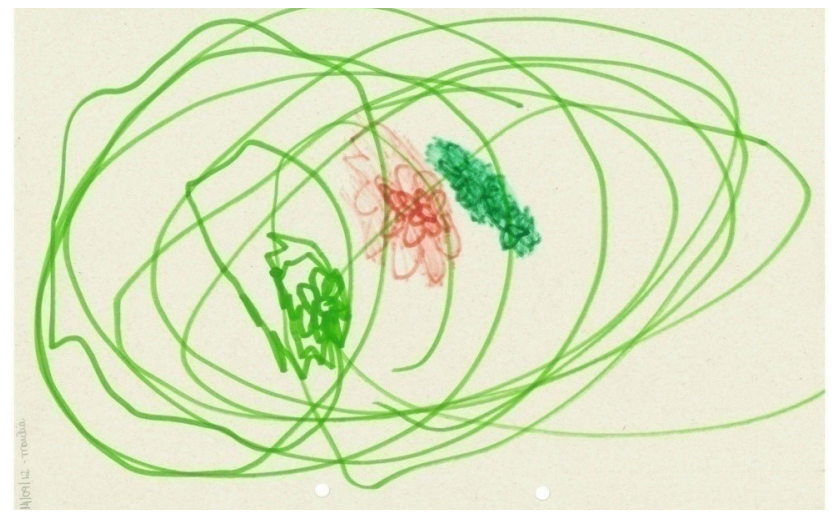

Figura 4. Flores.

Fonte: Prontuário de atendimento da Clínica-Escola de Psicologia do Unilavras.

Nas próximas sessões, Maria não mais apresenta agressividade e percebo que quando seus desenhos perdem forma, novos significantes surgem em meio às suas produções: "podemos entender, então, que as

240 Estilos clin., São Paulo, v. 22, n. 2, maio/ago. 2017, 230-245. 
brincadeiras e os jogos infantis se constituem como um trabalho de elaboração" (Benveniste, Lima \& Mandelbaum, 2004, p. 83). Veja que a agressividade foi substituída pelo desenho, pois agora os significantes revelam-se por meio da perda de forma na produção gráfica de Maria.

Após treze meses de terapia, Maria continua a desenhar. Em uma de suas produções ela esboça movimentos circulares e colore. Ao terminar, entrega o desenho a mim e elucida que se travava de um sol (Figura 5). Inicio uma conversa a respeito do desenho e pergunto quem seria o sol. Maria diz que ele se chama Mateus - colega de classe quando ela ainda frequentava a escola regular, a única criança que Maria permitia aproximação.

Figura 5. Sol.

Fonte: Prontuário de atendimento da Clínica-Escola de Psicologia do Unilavras.

Daí decorre a possibilidade de projeção desta vivência relacional na representação plástica que já descrevemos sob o ângulo de antropomorfização. À minha pergunta: "Quem seria o sol?”, pergunta que coloca no condicional a possibilidade de fazer associações acerca do sol, a criança pode responder: "O sol seria papai, a grama seria Fulano...". Eu poderia ainda lhe perguntar: "Se você estivesse em seu desenho, onde é que estaria?", não esquecendo que a criança pequena só pode entrar em relação através da projeção (Dolto, 2008, p. 20).

Ao completar dezoito meses de acompanhamento psicológico, Maria esboça um desenho que ilustra sua elaboração. Ela faz um desenho azul ao lado direito da folha, diz que é um cocô, o meu cocô (da terapeuta), diz que o jogou no teto da sala (joga um giz de cera no chão mostrando-me como seria). Ao continuar sua produção, ela desenha uma flor vermelha que se mescla ao desenho anterior. Este é um desenho marcante de Maria, uma vez que as flores aparecem em toda 
sua trajetória na terapia. Nesse desenho interpreto que estávamos Maria e eu, a parte mesclada diz da transferência. Ainda que haja um ponto de junção nos dois desenhos, é notável que não somos uma só, pois parece que agora Maria possui algum controle sobre o Outro (manipula o cocô), não sendo invadida por ele (pelo Outro) (Figura 6).

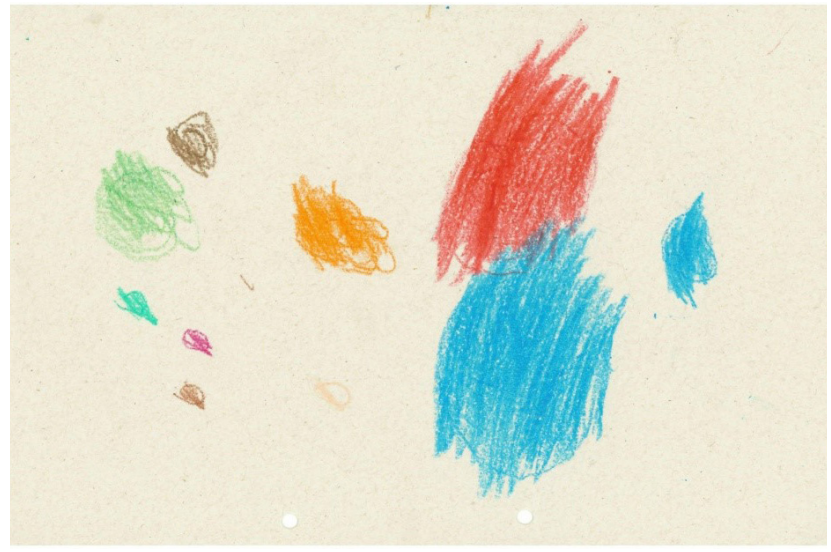

Figura 6. Cocô.

Fonte: Prontuário de atendimento da Clínica-Escola de Psicologia do Unilavras.

É relevante ressaltar que assim que Maria apresenta-se sob responsabilidade da tia, demonstra grandes passos em direção à constituição subjetiva, tanto no que diz respeito às elaborações que ocorriam por meio de suas produções como em relação ao contato social, pois aos cuidados da tia Maria tem maior contato com outras pessoas, e a "aposta antecipatória" faz parte dos constituintes daquela família.

Acompanhei-a por um ano e oito meses, e, até então, Maria não apresentava agressividade, uma vez que conseguia dizer a respeito de suas vontades sem usar a agressão física. Desse modo, Maria usufruía de sua vida social, frequentava lugares públicos (o que antes não acontecia) e estava prestes a voltar a estudar na Apae da cidade. Maria apresentava pouca fala ecolálica. Ela restringia sua fala a determinadas pessoas; porém, àquelas de seu convívio diário não demonstrava dificuldades. 


\section{Conclusão}

Por meio do conhecimento teórico vinculado à interpretação dos desenhos e por meio da discussão decorrente de tais fatores, constatou-se que tal produção gráfica é uma ferramenta de auxílio que contribuiu para a constituição subjetiva de Maria. É possível dizer acerca de seus passos em direção à constituição subjetiva após o início de suas atividades lúdicas, uma vez que seus desenhos sofriam mudanças no que se refere às formas, bordas e aos conteúdos simbólicos. Esses processos ocorreram a partir do momento que houve uma aposta no sujeito e propiciaram a Maria condições de desfrutar de algum controle sobre o Outro, diferenciando-se dele.

Nota-se que após o falecimento de Lourdes, Maria destaca-se em sua constituição subjetiva, uma vez que a mãe se demonstrava como uma figura castradora e em ausência de aposta subjetiva. Portanto, parece maleável a Maria lidar com a figura materna em seu discurso, visto que Lourdes aparece em suas produções.

Neste caso, o desenho atuou como facilitador no processo de aceitação da presença do Outro, por meio de possíveis elaborações que favoreceram o início de uma construção da imagem do corpo próprio.

Além disso, ocorreram diversas elaborações por meio do contexto lúdico, pois Maria não mais apresentava agressividade, visto que a paciente conseguia dizer de suas vontades sem usar a agressão física, o que possibilitou que desfrutasse de sua vida social novamente. Maria voltou a frequentar lugares públicos e houve possibilidade de voltar a estudar na Apae da cidade.

Por meio deste estudo, é possível dizer que a criança autista possui grandes possibilidades quanto a constituir-se como sujeito, inscrever-se no simbólico e tornar-se um ser desejante. Como discutido, o autista é um ser capaz de fazer uso do discurso, ainda que esta seja uma ideia que apresenta diversas controvérsias no campo de estudo da linguagem. Portanto, há de se pensar em possíveis e futuros estudos acerca dessa temática no autismo, principalmente no que se refere às estereotipias e ecolalias.

THE INFLUENCE OF DRAWING IN PSYCHOANALYTICAL PRACTICE FOR SUBJECT'S CONSTITUTION: A CASE STUDY ON CHILDHOOD AUTISM

\footnotetext{
Abstract

This paper aims to discuss the use of drawing as an auxiliary tool for the subjective constitution of an autistic patient, whose case was studied through the selection and interpretation of drawings significant to its comprehension. Based on theoretical knowledge and on the interpretation of such drawings, it was observed that such graphical production was relevant when considering the subjective constitution of the patient in question. After starting playful activities, the patient showed ability to experience some control over the Other and differentiate herself from him.
}

Index terms: autism; constitution; drawing; psychoanalysis. 


\section{LA INFLUENCIA DEL DIBUJO EN LA CLÍNICA \\ PSICOANALÍTICA PARA LA CONSTITUCIÓN DEL SUJETO: UN ESTUDIO DE CASO SOBRE EL AUTISMO INFANTIL}

\section{RESUMEN}

Este artículo tiene como objetivo discutir el uso del dibujo como herramienta auxiliar en la constitución subjetiva de una paciente autista, cuyo caso ba sido estudiado por medio de selección e interpretación de dibujos significativos para su comprensión. Por medio del conocimiento teórico vinculado a la interpretación de los dibujos se constató que tal producción gráfica fue relevante en lo que se refiere a la constitución subjetiva de la paciente en cuestión. Es posible decir que después del inicio de las actividades lúdicas, la paciente obtuvo condiciones de disfrutar de algún control sobre el Otro, diferenciándose de él.

Palabras clave: autismo; constitución; dibujo; psicoanálisis.

\section{REFERÊNCIAS}

Abramovitch, S. (2001). O diagnóstico de autismo infantil na história da psiquiatria. Marraio, (2), 83-88.

Ansermet, F. (2003). Clínica da origem: a criança entre a medicina e a psicanálise. (D. A. Seidl, trad.). Rio de Janeiro, RJ: Contracapa.

Benveniste, A., Lima, F. M. S., \& Mandelbaum, L. (2004). Biblioteca infantil: espaço de histórias. In J. M. L. Ribeiro, \& K. A. C. Monteiro (Orgs.), Autismo e psicose na criança: trajetórias clínicas (pp. 78-87). Rio de Janeiro, RJ: 7 Letras.

Bruder, M. C. R., \& Brauer, J. F. (2007). A constituição do sujeito na psicanálise lacaniana: impasses na separação. Psicologia em Estudo, 12(3), 513-21. doi: http://dx.doi.org/10.1590/ S1413-73722007000300008

Catão, I. (2009). O bebê nasce pela boca: voz, sujeito e clínica do autismo. São Paulo, SP: Instituto Langage.

Corgosinho, R. (2001). Sobre o diagnóstico de autismo em crianças muito pequenas. Marraio, (2), 51-5.

Dolto, F. (2008). A imagem inconsciente do corpo. São Paulo, SP: Perspectiva.

Freud, S. (1996). Os instintos e suas vicissitudes. In S. Freud, Edição standard brasileira das obras psicológicas completas de Sigmund Freud (J. Salomão, trad., Vol. 14, pp. 116-144). Rio Janeiro: Imago. (Trabalho original publicado em 1914)

244 Estilos clin., São Paulo, v. 22, n. 2, maio/ago. 2017, 230-245. 
Jerusalinsky, A. (2012). Psicanálise do autismo. São Paulo, SP: Instituto Langage.

Kanner, L. (1997). Os distúrbios autísticos do contato afetivo. In P. S. Rocha (Org.), Autismos (pp. 111-170). São Paulo, SP: Escuta. (Trabalho original publicado em 1943)

Lacan, J. (1979). O seminário, livro 11: os quatro conceitos fundamentais da psicanálise, 1964. Rio de Janeiro, RJ: Jorge Zahar.

Lopes, T. J. S., \& Bernardino, L. M. F. (2011). O sujeito em constituição, o brincar e a problemática do desejo na modernidade. Revista Mal-Estar e Subjetividade, 11(1), 369-95.

Nascimento, E. M. V. (2001). A questão da pulsão na clínica do autismo. Marraio, (2), 57-61.

Nominé, B. (2001). O autista: um escravo da linguagem. Marraio, (2), 11-23.

Novaes, M. A. A. (2004). Os destinos da alienação e as consequências sobre a transferência: efeitos de uma "prática de vários". In J. M. L. Ribeiro, \& K. A. C. Monteiro (Orgs.), Autismo e psicose na criança: trajetórias clínicas (pp. 88-98). Rio de Janeiro, RJ: 7 Letras.

Rêgo, F. L. B., \& Carvalho, G. M. M. (2006). Aquisição de linguagem: uma contribuição para o debate sobre autismo e subjetividade. Psicologia: Ciência e Profissão, 26(1), 12-25. doi: http:// dx.doi.org/10.1590/S1414-98932006000100003

Ribeiro, J. M. L., \& Monteiro, K. A. C. (Orgs.). (2004). A "prática entre vários" e a intervenção do sujeito. Rio de Janeiro, RJ: 7 Letras.

Seicman, M. (2000). O psicanalista, o autista e o autismo. Revista Latino-americana de Psicopatologia Fundamental, 3(1), 117-30. doi: http://dx.doi.org/10.1590/1415-47142000001008

Vorcaro, A., \& Lucero, A. (2010). Entre real, simbólico e imaginário: leituras do autismo. Revista Psicologia Argumento, 28(61), 147-57.

1. Nome fictício

2. Nome fictício

renatacgoncalves@hotmail.com

Rua Maria Madalena Fernandes, 27/102 37200-000 - Lavras - MG - Brasil. 